\title{
A AUTENTICIDADE COMO INSTRUMENTO DE ORIENTAÇÃO PARA A ADAPTAÇÃO DO PATRIMÔNIO CULTURAL BRASILEIRO À ACESSIBILIDADE UNIVERSAL: O CASO DO ADRO DO CONVENTO FRANCISCANO EM OLINDA (PE)
}

\author{
FERREIRA, Oscar Luís (1); \\ MÁXIMO, Marco Aurélio da Silva (2); \\ ZERBINI, Ana Suely (3) \\ (1) Universidade de Brasília, Doutor em Arquitetura e Urbanismo \\ e-mail:oscar@unb.br \\ (2) Instituto do Patrimônio Histórico e Artístico Nacional, Engenheiro Civil \\ e-mail: marco.maximo@iphan.gov.br \\ (3) Universidade de Brasília, Arquiteta e Urbanista \\ e-mail:zerbiniana@gmail.com
}

\begin{abstract}
RESUMO
O Patrimônio Cultural Brasileiro deve ser acessível para que se garanta a todos o direito constitucional de livre acesso à cultura e aos bens culturais nacionais. No entanto, a execução de adaptações para a acessibilidade requer respeito aos valores atribuídos aos bens patrimoniais. Como forma de discutir a importância da acessibilidade e o respeito a autenticidade de bens patrimoniais em qualquer intervenção, este artigo lança um olhar sobre o Adro do Convento franciscano em Olinda (PE) a partir do conceito de autenticidade e da construção de um método para coleta de informações sobre a atribuição de valores aos bens patrimoniais.
\end{abstract}

Palavras chave: Autenticidade; Acessibilidade; Convento Franciscano.

\section{ABSTRACT (11 PTS, NEGRITO)}

The Brazilian Cultural Heritage must be accessible to guarantee the constitutional right of free access to all to culture and national cultural assets. However, the implementation of adaptations for accessibility requires respect to values of the heritage. As a way to discuss the importance of accessibility and respect for the authenticity of cultural heritage in any intervention, this article takes a look at the Adro of the Franciscan Convent in Olinda (PE) from the authenticity concept and the construction of a method in order to assign information on the values to the cultural assets.

Keywords: Authenticity; Accessibility; Franciscan Convent.

\section{INTRODUÇÃO}

Em 1535, o nobre português Duarte Coelho fundou a cidade de Olinda, que se tornou um importante centro exportador de pau-brasil e açúcar, A partir do final do século XVI, recebeu 
a chegada das primeiras ordens religiosas, em especial, em 1583, a ordem dos franciscanos.

Segundo Germain Bazin (1958), no ano de 1583 foi concedido o Alvará de Doação das terras de Olinda à Congregação Franciscana para fundação do primeiro Convento da Ordem no Brasil. Em 1585 os frades franciscanos chegaram a Olinda e receberam de Maria da Rosa, irmã da Ordem Terceira de São Francisco, doação da capela de Nossa Senhora das Neves assim como terrenos em torno da capela. O Convento recebeu acréscimos até 1590, sob coordenação do Frei Custódio dos Anjos. Em 1631 o conjunto foi incendiado durante a invasão holandesa ao Brasil e ficou abandonado.

Em 1654, os holandeses são expulsos pelas forças portuguesas e a reconstrução da Vila de Olinda lentamente iniciada. Em 1676, a vila é elevada à categoria de cidade e é provavelmente deste período, final do século XVII, o início da reconstrução do Convento de Nossa Senhora das Neves. A partir da segunda metade do século XVII, após a Restauração Pernambucana, iniciaram-se as obras de reconstrução do Convento. Segundo Bazin (1958), há indícios de que a reconstrução seja deste período, devido à existência no local de pedra tumular do Frei Joseph de Santo Antônio, falecido em 1686, e arcada próxima à sacristia que denota ter sido obra executada por volta de 1660 em virtude de suas características formais e estilísticas. Grande parte das obras de construção da azulejaria e dos trabalhos artísticos foram realizados no decorrer do século XVII. Alguns acréscimos, dentre eles, o do frontispício, foram concluídos até 1755, posto que, as janelas térreas da portaria indicam 0 ano de 1754. Em frente ao frontispício encontra-se uma 'cruz', vestígio de antiga via-sacra que se realizava na cidade e parte do ritual religioso católico. Outras adições foram executadas ao longo dos séculos XVIII e XIX, até adquirir a forma e o acervo dos dias atuais (BAZIN, 1958).

O Convento de Nossa Senhora das Neves é o mais antigo Convento da Ordem Franciscana do Brasil. O conjunto está tombado como Igreja e Convento de Nossa Senhora das Neves, capela, casa de oração e claustro dos Terceiros Franciscanos, inclusive o Adro, o Cruzeiro e toda a área da antiga cerca conventual.

Em 1982, Olinda recebe o título de Patrimônio Cultural da Humanidade, concedido pela Unesco. A cidade passa a receber diariamente centenas de turistas em busca de sua arte e festejos populares, de sua arquitetura quatrocentista em meio a uma topografia acentuada, compondo junto à natureza exuberante uma paisagem ímpar, em meio a arrecifes e colinas. A acessibilidade é um conceito do final do século XX e o conjunto arquitetônico do Convento existe há mais de 430 anos. Tem em comum, acessibilidade e Convento (patrimônio cultural), o ser humano, sua criatividade e fé (UBIERNA, 2011).

Ao situarmos o binômio que compõe o cerne deste artigo, patrimônio cultural e acessibilidade, iniciamos pela cidade de Olinda, provavelmente fundada em 1535 e elevada a Vila em 1537, que rapidamente desenvolveu-se com a expansão da produção de açúcar oriundo dos engenhos que se instalaram na várzea do rio Capibaribe, no século XVI. A partir do final do século XVI, recebeu a chegada das primeiras ordens religiosas, em especial, em 1583, a ordem dos franciscanos. Em 1585, a ordem recebeu por doação a capela de Nossa Senhora das Neves, além de alguns terrenos onde edificou o Convento de Nossa Senhora das Neves. A edificação recebeu acréscimos até o final do século XVI, porém, foi destruída em 1631 durante o incêndio de Olinda quase dois anos após a invasão e conquista pelos holandeses da capitania de Pernambuco. A cidade foi abandonada e a sede da capitania, sob domínio estrangeiro, mudou-se para a vila de Recife. Em 1654, os holandeses são expulsos pelas forças portuguesas e a reconstrução da Vila de Olinda lentamente iniciada. Em 1676, a vila é elevada à categoria de cidade e é provavelmente deste período, final do século XVII, o início da reconstrução do Convento de Nossa Senhora das Neves. 


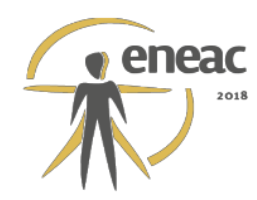

\section{O ADRO DO CONVENTO FRANCISCANO}

Sobre o Adro não foram encontrados documentos que atestem a data exata de sua construção ou a do Cruzeiro, contudo, sua delimitação aparece em mapa de 1630. Nota-se a existência do Adro em frente à Igreja de Nossa Senhora das Neves, com espaço demarcado, assim como um antigo caminho, interligando o Convento Franciscano à Igreja da Graça e ao Seminário de Olinda. Com esta configuração, este complexo urbano e arquitetônico foi tombado em 1938 pelo Instituto do Patrimônio Histórico e Artístico Nacional (IPHAN). À época do tombamento o conjunto estava completo e permaneceu com a mesma leitura espacial e arquitetônica até o final do século XX. Na primeira década do século XXI o Adro foi objeto de uma intervenção que rompeu a unidade do conjunto.

O conjunto formado pelo Adro, pelo Cruzeiro e pela torre recuada da fachada são especificidades de alguns Conventos da Ordem Franciscana. Do Cruzeiro é possível a apreensão da fachada principal da igreja. Encontra-se geralmente em posição simetricamente oposta ao frontispício. No caso do Convento Franciscano de Olinda, o Adro, além de ser uma solução urbanística, tira partido da topografia do terreno do qual resulta um conjunto integrado ao sítio, com igreja e Convento localizados em plano mais elevado.

Nesta congregação, o Adro (Figura 1), o Cruzeiro e o Convento constituíam um conjunto urbano-arquitetônico integrado e harmonioso. Nenhuma intervenção adicionou elementos que extinguissem a unidade deste conjunto. A coesão desses elementos se percebe por meio da integração entre a calçada em frente à igreja, que antecede a Galilé, interliga-se ao Adro e deste, ao Cruzeiro. Imagens da década de 1970, mostram o Adro pavimentado em diferentes planos. O primeiro, a calçada, ligada à igreja, encontra-se revestida com tijoleira artesanal; o segundo rebaixado, pavimentado com pedras graníticas retangulares em tamanhos diferentes configurando a rua, e outros dois inclinados, formando a rampa pavimentada com pedras graníticas retangulares que conduzem ao Cruzeiro. A configuração atual do Adro de São Francisco resulta de um projeto de intervenção para recuperação de espaços públicos, ação pertinente ao Plano de Reabilitação do Sítio Histórico de Olinda, realizado pela Prefeitura de Olinda, em 2001.

\section{Figura 1 - Trecho do Adro do Convento Franciscano, Olinda (PE)}

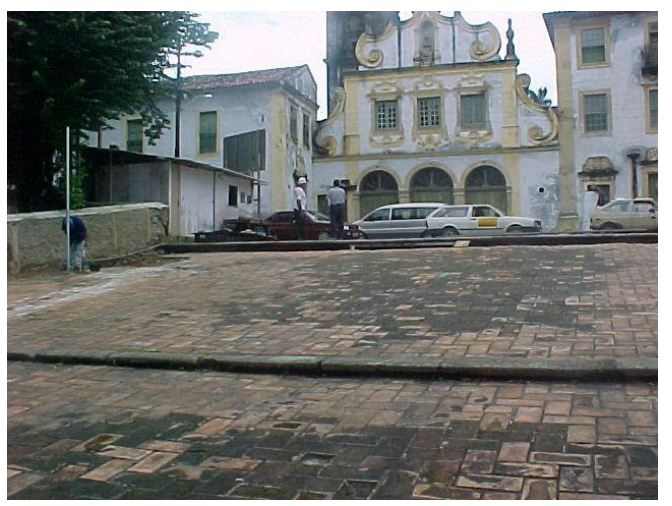

Fonte: Arquiteta Ana Suely Zerbini

Antes da intervenção, o Adro encontrava-se sem passeio público, com duas escadas laterais, peitoril com grade de ferro que segregava a rampa e os elementos constitutivos do conjunto, ou seja, igreja, Adro e largo do Cruzeiro. Do ponto de vista arquitetônico e urbano, tal configuração fragmentou o espaço, outrora configurado como um todo, e comprometeu a relação Adro-igreja, ao criar uma forte barreira urbanística e visual, uma vez que a leitura 


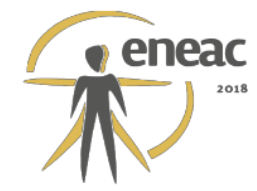

espacial ficou comprometida pelo gradil e pelo desnível entre a Rua São Francisco e a rampa que interligava o Adro à Travessa São Francisco.

Essa conformação acarreta dificuldades à acessibilidade, na medida em que se fragmentou o passeio público e a continuidade do ambiente. Observou-se ainda uso inadequado do espaço, ou subutilização do mesmo, criação de grandes problemas para manutenção, conservação e sustentabilidade do ambiente, tais como presença de vegetação nos achados arqueológicos, rampa e Cruzeiro, degradação ambiental, dentre outros. Para este estudo considera-se o Adro do Convento Franciscano apenas o espaço delimitado pelos muros laterais, pelo Convento e pelo encontro das ruas São Francisco e São José Belarmino da Silva.

\section{ACESSIBILIDADE E AUTENTICIDADE}

\subsection{Atualização da Legislação Brasileira sobre Acessibilidade e Patrimônio}

No ano de 2004, o Decreto Federal no 5.296/2004 regulamentou as leis no 10.048/2000 e 10.098/2000, consolidando toda a legislação anterior. Em 06 de julho de 2015, foi sancionada a lei no 13.146/2015, que instituiu a Lei Brasileira de Inclusão da Pessoa com Deficiência, o chamado estatuto da pessoa com deficiência, destinada a assegurar e a promover, em condições de igualdade o exercício dos direitos e das liberdades fundamentais por pessoa com deficiência, visando à sua inclusão social e cidadania (BRASIL, 2015).

A Associação Brasileira de Normas Técnicas (ABNT) - editou em 2004 a norma brasileira NBR-9050/2004 que estabeleceu os critérios e parâmetros técnicos de acessibilidade a serem observados nas fases de projeto, construção, instalação e adaptação de edificações, mobiliário, espaços e equipamentos urbanos. Tal norma foi vinculada ao Decreto Federal no 5.296/2004, e seu cumprimento tornou-se obrigatório. Em 11 de setembro de 2015, a ABNT editou a revisão da norma. A NBR-9050/2015 apresenta um texto mais explicativo e detalhado, no geral.

O Instituto do Patrimônio Histórico e Artístico Nacional (IPHAN) - publicou em 2003 a Instrução Normativa ํㅡ 01 , com as considerações básicas sobre a adaptação de bens culturais imóveis acautelados em nível federal, baseada nas Leis ํㅜ 10.048/2000 e ํㅡㄴ 10.098/2000, além das normas da ABNT. Em 28 de fevereiro de 2014, o Iphan publicou a Instrução Normativa no 01 alterando a resolução de 2003, acrescentando a aplicação da mesma a "intervenções em conjuntos urbanos consistentes em drenagem urbana, saneamento ambiental, embutimento de fiação elétrica, pavimentação, implantação de sinalização de trânsito ou turística e implantação de mobiliário urbano" (IPHAN, 2014).

Toda esta normativa está vinculada porém, ao marco disposto na Instrução Normativa No. 01 que impõe que "o limite para a adoção de soluções em acessibilidade decorerá da avaliação sobre a possibilidade de comprometimento do valor testemunhal e da integridade estrutural resultantes" (IPHAN, 2003). Por valor testemunhal podemos entender todos os valores atribuídos a um determinado bem oriundos da relação de identidade construída por determinada sociedade ou grupo e que the fortalecem ou determinam a preservação. A significância cultural, a preservação dos diversos significados atribuídos a um bem, que sabiamente não o vincula a um valor preponderante como, por exemplo, o valor histórico ou artístico, mas ao conjunto de valores que o configuram possibilitando assim 0 estabelecimento de procedimentos de intervenção que garantam a sua preservação plena, como indicado pela Carta de Veneza (1964). 


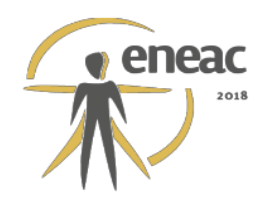

\subsection{Autenticidade}

O imperativo proposto, em 1964, pela Carta de Veneza, qual seja, o de transmitir para as gerações futuras na plenitude de sua autenticidade não apenas os bens monumentais, mas todos aqueles que ao longo de sua existência adquiriram significância cultural (CURY, 2004, p. 91), portanto, para transmitir será antes necessário preservá-lo em toda a sua autenticidade, ou seja, devemos conservar o patrimônio cultural com todos os seus valores, e não apenas com uma de suas principais dimensões que the qualificam como tal. Autenticidade significa garantir à 'originalidade e a verdade' das fontes históricas, da expressão artística e autoral, dos aspectos materiais e estruturais, bem como das expressões de tradição e identidade cultural do patrimônio cultural. Conforme indica a Declaração de San Antonio (1996), a autenticidade está na identificação, avaliação e interpretação destes valores atribuídos a um bem. Ao ferirmos valores por meio da intervenção física sobre aspectos, como desenho e forma, materiais e substância, uso e função, tradições e técnicas, localização e espaço ou espírito e sentimento ferimos portanto, sua autenticidade. Ou seja,

dependendo da natureza do patrimônio cultural, seu contexto cultural e sua evolução através do tempo, os julgamentos quanto a autenticidade devem estar relacionados à valorização de uma grande variedade de pesquisas e fontes de informação. Estas pesquisas e levantamentos devem incluir aspectos de forma e desenho, materiais e substância, uso e função, tradições e técnicas, localização e espaço, espírito e sentimento, e outros fatores internos e externos. O emprego destas fontes de pesquisa permite delinear as dimensões específicas do bem cultural que está sendo examinado, como artísticas, históricas, sociais e científicas (CURY, 2004, p. 322).

\section{O MÉTODO}

De modo a garantir a preservação integral de um bem é necessário diagnosticar os valores a ele atribuídos, por meio da avaliação da autenticidade. Para então desenvolver-se um plano de ação de conservação da edificação e também planos de intervenção que não interfiram ou que apresentem mínima interferência sobre os valores identificados. Preservar valores significa também garantir a identidade do bem. Toda e qualquer intervenção no patrimônio construído apresenta algum impacto sobre os aspectos que conformam suas dimensões e, portanto, seus valores e a maneira com que o grupo ou comunidade se identifica com este bem. Estes aspectos podem ser relacionados aos possíveis impactos causados por intervenções para a acessibilidade:

- Forma e Desenho. Intervenções com o intuito de garantir a acessibilidade física de um monumento ou patrimônio construído podem interferir com a forma original e a concepção de um edifício;

- Materiais e Substância. Ainda que nas intervenções para acessibilidade sejam utilizadas adições ou anexos a um monumento o que, de fato, poderia apresentar um baixo grau de interferência na substância ou materiais originais da edificação, estas devem ser obrigatoriamente avaliadas antes da realização de qualquer ação;

- Uso e Função. As intervenções que garantam a acessibilidade física a um determinado bem podem interferir com o uso original ou com a distribuição original de seu mobiliário, bem como, modificar a sua função o que deve ser devidamente informado aos usuários quando tal ação não puder ser evitada ou contornada;

- Tradições e Técnicas. As intervenções para acessibilidade podem acrescentar à 


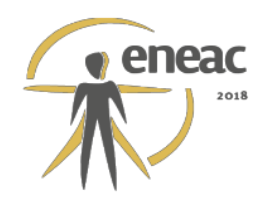

edificação diferentes tipos de materiais, em especial, os materiais modernos, como o aço inoxidável, o vidro e/ou o concreto que podem interferir com o processo de manutenção do patrimônio construído. $E$, quando nos referimos à preservação do patrimônio moderno, este tipo de intervenção pode ser ainda mais ariscado, pois a distinção entre "novo" e "antigo" é substancialmente mais difícil;

- Localização e Espaço. O acréscimo de longas rampas, sinalização tátil, mapas táteis ou outros elementos que garantam a acessibilidade podem alterar profundamente 0 espaço ou a compreensão da implantação original do bem;

- Espírito e Sentimento. Para Barry Rowney (2004), este é o aspecto mais efêmero da constituição dos valores e da autenticidade de um bem e também aquele que apresenta "considerável influência na avaliação da autenticidade" devido a sua direta relação com a identidade. As intervenções para a acessibilidade, se bem executadas, podem reforçar tais laços.

\section{RESULTADOS}

As principais não conformidades identificadas quanto ao atendimento da acessibilidade, da segurança e ao uso adequado do bem foram: ausência de sinalização (turística, interpretativa e direcional para deficientes), irregularidades no pavimento (lacunas, peças quebradas, desagregação), ausência de passeio, acúmulo de vegetação, necessidade de consolidação de elementos (risco de acidentes e perdas), ausência de vagas em estacionamento para deficientes, ausência de rota acessível, necessidade de criar meios de redução de tráfego na rua adjacente ao Convento, ausência de rampas como alternativas das escadas laterais, ausência de mobiliário urbano e iluminação pública deficiente.

Na década de 1970, houve uma intervenção que instalou no piso do Adro lajes de granito assentadas sobre uma base de concreto. O piso foi alterado em diversas épocas, tendo sido aterrado com diversos materiais como barro, terra e restos de demolição. De 2001 a 2004, o Adro passou por intervenções que não foram concluídas, ações que fragmentaram o espaço, interrompendo a relação Adro-igreja, e isso provocou subutilização do local além de problemas de manutenção e conservação. Desta maneira compreende-se que a espacialidade do Adro, e sua unidade com outros elementos, foi perdida ao longo do tempo.

Todas essas alterações ao longo do tempo, inclusive após o tombamento, ao mesmo tempo que prejudicaram o bem, hoje oferecem certa liberdade para propostas de intervenção, e o principal referencial para intervenções encontra-se presente nas informações sobre as condições do bem na época do tombamento, ou seja, ainda em 1938.

Dentre outras diretrizes para a intervenção está a utilização do anteprojeto da Prefeitura de Olinda, de autoria do arquiteto Emanuel Almeida, como ponto de partida, além é claro, da própria configuração espacial em que o Adro se encontrava à época do tombamento, em 1938 (MOREIRA, 2007).

A Matriz de Autenticidade (Tabela 1) apresenta a análise dos valores da edificação e a Matriz de Autenticidade e Acessibilidade (Tabela 2) apresenta uma possibilidade de avaliação de como as intervenções para resolver as não conformidades podem interferir, alterando ou danificando as dimensões e aspectos do bem cultural. 


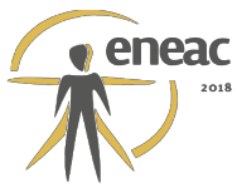

Tabela 1 - A Matriz de Autenticidade

\begin{tabular}{|c|c|c|c|c|}
\hline \multirow{2}{*}{ Aspectos } & \multicolumn{4}{|c|}{ Dimensões } \\
\hline & Artística & Histórica & Social & Científica \\
\hline & $\begin{array}{l}\text { Na concepção } \\
\text { original o Adro era } \\
\text { inclinado e fechado } \\
\text { por muros e portão } \\
\text { de acesso ao pátio } \\
\text { do Cruzeiro. o } \\
\text { conjunto está } \\
\text { segregado, } \\
\text { diferentemente da } \\
\text { época do } \\
\text { tombamento (1938), } \\
\text { quando Convento, } \\
\text { Adro e Cruzeiro } \\
\text { formavam unidade } \\
\text { com leitura espacial } \\
\text { e arquitetônica. }\end{array}$ & 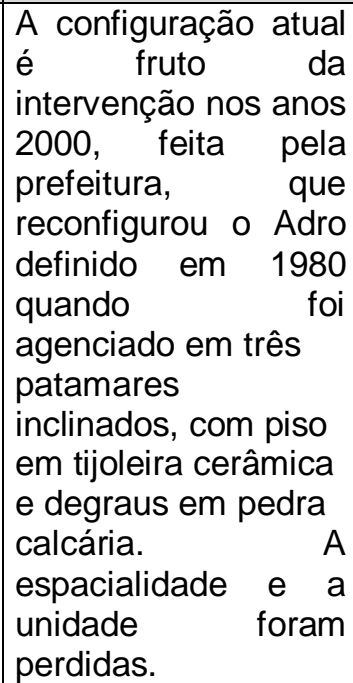 & $\begin{array}{lr} & \\
\text { O estado } & \text { de } \\
\text { conservação atual é } & \text { péssimo. Limpezas } \\
\text { rotineiras com jatos } \\
\text { d'água } & \text { tem } \\
\text { prejudicado } & \text { a } \\
\text { integridade } & \text { de } \\
\text { elementos } & \text { e } \\
\text { materiais. } & \text { A } \\
\text { segregação } & \text { do } \\
\text { conjunto contribuiu } \\
\text { para ser um local } \\
\text { ermo. }\end{array}$ & $\begin{array}{l}\text { O Convento de } \\
\text { Olinda (PE) é um } \\
\text { importante } \\
\text { exemplar } \\
\text { concepção } \\
\text { franciscana no } \\
\text { Brasil, assim como } \\
\text { os Conventos de } \\
\text { Igarassu (PE) e de } \\
\text { João Pessoa (PB). } \\
\text { Isso mostra a } \\
\text { relevância de sa } \\
\text { preservação. }\end{array}$ \\
\hline $\begin{array}{c}\text { 2. Materiais } \\
e \\
\text { Substância }\end{array}$ & $\begin{array}{l}\text { Em } 2002 \text { foram } \\
\text { reveladas as ruínas } \\
\text { de calçada em pedra } \\
\text { calcária (século } \\
\text { XVI). Até } 1970 \text { tinha } \\
\text { piso em vários } \\
\text { planos: calçada em } \\
\text { tijoleira artesanal, } \\
\text { rua e rampas em } \\
\text { pedras graníticas } \\
\text { retangulares, e o } \\
\text { Cruzeiro } \\
\text { cantaria. Hoje as } \\
\text { pedras e tijolos dos } \\
\text { muros arastos. estão } \\
\text { expostos. }\end{array}$ & $\begin{array}{l}\text { O piso do Adro e } \\
\text { seus muros não } \\
\text { eram originalmente } \\
\text { planos. O Adro } \\
\text { sofreu soterramentos } \\
\text { ao longo do tempo, } \\
\text { com o uso de barro, } \\
\text { terra e restos de } \\
\text { demolição. Em } 1970 \\
\text { uma intervenção } \\
\text { instalou no piso do } \\
\text { Adro lajes de granito } \\
\text { assentadas sobre } \\
\text { base de concreto. }\end{array}$ & 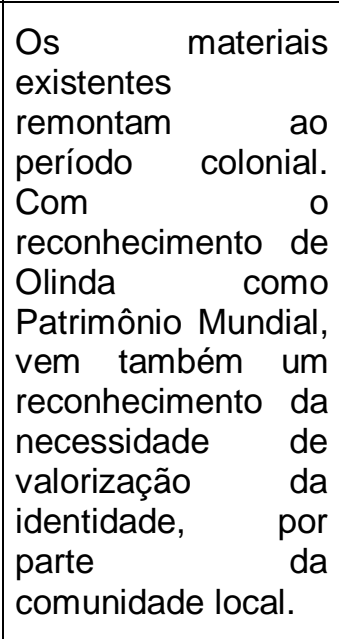 & 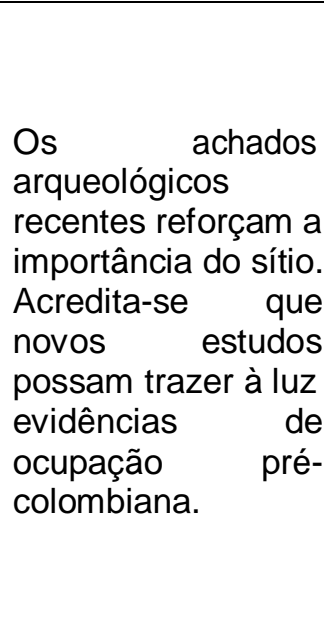 \\
\hline & 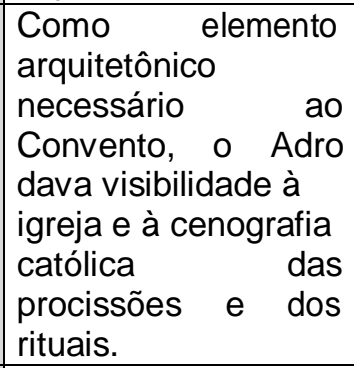 & $\begin{array}{lr}\text { O local foi } & \text { utilizado } \\
\text { em sepultamentos } \\
\text { secundários. } & \text { Foi } \\
\text { instalada a primeira } \\
\text { escola de } & \text { educação } \\
\text { indígena r } & \text { (século } \\
\text { XVI). } & \text { Rituais } \\
\text { religiosos r eram } & \text { realizados no local. }\end{array}$ & $\begin{array}{l}\text { A fragmentação do } \\
\text { conjunto prejudica o } \\
\text { uso como espaço } \\
\text { de encontros e de } \\
\text { práticas religiosas. } \\
\text { O Convento é um } \\
\text { ponto turístico. }\end{array}$ & $\begin{array}{l}\text { Estudos sobre } \\
\text { autenticidade e } \\
\text { acessibilidade } \\
\text { podem evitar que } \\
\text { adaptações sejam } \\
\text { realizadas de forma } \\
\text { inadequada. }\end{array}$ \\
\hline $\begin{array}{c}4 . \\
\text { Tradições e } \\
\text { Técnicas }\end{array}$ & $\begin{array}{l}\text { Identificam-se várias } \\
\text { técnicas construtivas } \\
\text { do período colonial, } \\
\text { como a cantaria, } \\
\text { alvenarias, } \\
\text { argamassa bastarda, } \\
\text { pisos em pedra e } \\
\text { tijoleira, muros em } \\
\text { pedra. }\end{array}$ & $\begin{array}{l}\text { Acredita-se que a } \\
\text { colina onde está o } \\
\text { Convento e o Adro } \\
\text { tenha passado por } \\
\text { ocupação indígena } \\
\text { Tupi, com vestígios } \\
\text { seixos e de carvão. }\end{array}$ & $\begin{array}{l}\text { Vandalismo } \\
\text { provocou perdas } \\
\text { dos achados } \\
\text { arqueológicos, } \\
\text { como de partes de } \\
\text { esqueletos. Há } \\
\text { pichações e } \\
\text { diversas patologias, } \\
\text { no Cruzeiro. }\end{array}$ & $\begin{array}{l}\text { Estudos das } \\
\text { técnicas } \\
\text { construtivas podem } \\
\text { contribuir na } \\
\text { preservação } \\
\text { revelando parte da } \\
\text { história e do } \\
\text { desenvolvimento } \\
\text { humano. }\end{array}$ \\
\hline
\end{tabular}




\begin{tabular}{|c|c|c|c|c|}
\hline \multirow{2}{*}{ Aspectos } & \multicolumn{4}{|c|}{ Dimensões } \\
\hline & Artística & Histórica & Social & Científica \\
\hline $\begin{array}{c}5 . \\
\text { Localização } \\
\text { e Espaço }\end{array}$ & $\begin{array}{l}\text { A visibilidade do } \\
\text { Convento, } \\
\text { favorecida pelo } \\
\text { Adro, é importante } \\
\text { fator estético na } \\
\text { concepção do } \\
\text { conjunto. O templo } \\
\text { fica instalado ao } \\
\text { fundo do espaço } \\
\text { delimitado pelos } \\
\text { muros, no topo da } \\
\text { colina. }\end{array}$ & $\begin{array}{l}\text { A delimitação do } \\
\text { Adro aparece em um } \\
\text { mapa de } 1630 \text {, e o } \\
\text { Cruzeiro r é } \\
\text { provavelmente do } \\
\text { ano de } 1700 . \\
\text { Acredita-se re que } \\
\text { rituais religiosos } \\
\text { aconteciam no } \\
\text { trajeto da Igreja da } \\
\text { Sé até o Convento. }\end{array}$ & $\begin{array}{l}\text { A valorização do } \\
\text { Convento e r seu } \\
\text { conjunto é ao } \\
\text { mesmo tempo a } \\
\text { valorização da } \\
\text { comunidade local e } \\
\text { de seus costumes. }\end{array}$ & $\begin{array}{l}\text { Estudar a } \\
\text { localização pode } \\
\text { revelar a forma de } \\
\text { ocupação do } \\
\text { espaço urbano e } \\
\text { sua evolução ao } \\
\text { longo do tempo. }\end{array}$ \\
\hline $\begin{array}{l}\text { 6. Espírito e } \\
\text { Sentimento }\end{array}$ & $\begin{array}{l}\text { O conjunto constitui } \\
\text { o percurso de ritos } \\
\text { religiosos. }\end{array}$ & $\begin{array}{lr}\text { O Adro é } & \text { um } \\
\text { ambiente } & \text { de } \\
\text { acolhimento, } & \text { de } \\
\text { transição entre o } \\
\text { profano e o sagrado, } \\
\text { marcando r } \\
\text { passagem da vida } \\
\text { laica à vida religiosa. }\end{array}$ & $\begin{array}{lr}\text { Há } & \text { várias } \\
\text { pichações } & \text { e } \\
\text { patologias, mesmo } \\
\text { assim o r uso } \\
\text { religioso do espaço } \\
\text { ainda é intenso. }\end{array}$ & $\begin{array}{lrr}\text { Estudos } & \text { sobre } & 0 \\
\text { conjunto } & \text { podem } \\
\text { demonstrar } & \text { como } \\
\text { se deu } & \text { a } \\
\text { construção } & \text { da } \\
\text { identidade } & \text { da } \\
\text { comunidade com o } \\
\text { local. }\end{array}$ \\
\hline
\end{tabular}

Fonte: Elaborada pelos autores

Tabela 2 - Matriz de Autenticidade e Acessibilidade Avaliação do Impacto das intervenções para a acessibilidade

\begin{tabular}{|c|c|c|c|c|}
\hline \multirow{2}{*}{ Aspectos } & \multicolumn{4}{|c|}{ Dimensões } \\
\hline & Artística & Histórica & Social & Científica \\
\hline $\begin{array}{c}\text { 1. Forma e } \\
\text { Desenho }\end{array}$ & $\begin{array}{l}\text { A configuração do Adro foi muito } \\
\text { alterada ao longo do tempo. A partir } \\
\text { do anteprojeto do arquiteto Emanuel } \\
\text { Almeida, com planos inclinados entre } \\
\text { o Cruzeiro e o Convento, pode-se } \\
\text { buscar o retorno à época do } \\
\text { tombamento, no entanto, esta é uma } \\
\text { ação que requer conhecimentos } \\
\text { técnicos e investimento financeiro. } \\
\text { Vagas de estacionamento, placas de } \\
\text { sinalização, sinalização tátil e de } \\
\text { rampa de acesso à galilé (reversível) } \\
\text { podem afetar negativamente, } \\
\text { devendo-se primar pela racionalidade } \\
\text { e harmonia. }\end{array}$ & $\begin{array}{l}\text { A rampa para } \\
\text { acesso à galilé, } \\
\text { o traffic calming } \\
\text { e a revitalização } \\
\text { do pavimento } \\
\text { não afetam } \\
\text { negativamente, } \\
\text { pois se mostram } \\
\text { pelo contraste. A } \\
\text { retirada das } \\
\text { escadas não é } \\
\text { problema. }\end{array}$ & 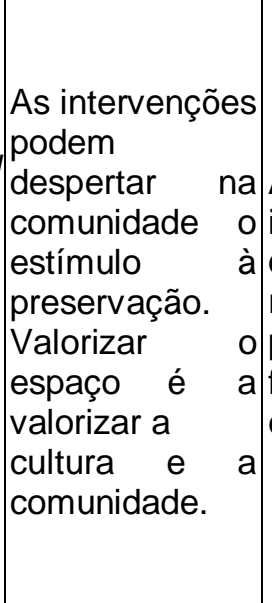 & $\begin{array}{l}\text { As } \\
\text { intervenções } \\
\text { devem ser } \\
\text { registradas } \\
\text { para viabilizar } \\
\text { futuros } \\
\text { estudos. }\end{array}$ \\
\hline $\begin{array}{c}\text { 2. Materiais } \\
e \\
\text { Substância }\end{array}$ & $\begin{array}{l}\text { Substituir o pavimento do Adro pode } \\
\text { afetar negativamente a leitura do } \\
\text { espaço e sua unidade. As pedras } \\
\text { existentes têm boa condição de } \\
\text { resistência e abrasividade. Deve-se } \\
\text { priorizar a reutilização dos materiais } \\
\text { existentes na pavimentação do Adro, } \\
\text { respeitando as inclinações } \\
\text { adequadas. A instalação de elementos } \\
\text { deve ser compatível com as pedras } \\
\text { existente, principalmente quanto à } \\
\text { fixação. }\end{array}$ & $\begin{array}{lr}\text { Mais que } & 0 \\
\text { contraste, deve- } \\
\text { se buscar } \\
\text { harmonia. } \\
\text { utilização } \\
\text { mesmo material } \\
\text { no piso deve ser } \\
\text { priorizada, mas } \\
\text { é importante } \\
\text { prever meios } \\
\text { para evitar erros } \\
\text { de interpretação. }\end{array}$ & $\begin{array}{l}\text { Manter } \\
\text { máximo } \\
\text { possível } \\
\text { materiais } \\
\text { preexistentes é } \\
\text { importante para } \\
\text { não afetar a } \\
\text { identidade da } \\
\text { comunidade } \\
\text { com o bem. }\end{array}$ & $\begin{array}{l}\text { Tornar } \\
\text { Patrimônio } \\
\text { mais } \\
\text { acessível é } \\
\text { democratizar } \\
\text { o acesso e do } \\
\text { uso, } \\
\text { contribuindo } \\
\text { para } \\
\text { preservar. }\end{array}$ \\
\hline
\end{tabular}




\begin{tabular}{|c|c|c|c|c|}
\hline \multirow{2}{*}{ Aspectos } & \multicolumn{4}{|c|}{ Dimensões } \\
\hline & Artística & Histórica & Social & Científica \\
\hline $\begin{array}{l}\text { 3. Uso e } \\
\text { Função }\end{array}$ & $\begin{array}{l}\text { Novos elementos podem prejudicar a } \\
\text { visibilidade do Convento a partir do } \\
\text { Adro, por isso deve-se primar pela } \\
\text { racionalidade. As intervenções podem } \\
\text { potencializar o uso turístico do local. } \\
\text { A instalação de corrimãos pode } \\
\text { auxiliar as pessoas com mobilidade } \\
\text { reduzida. A retirada das escadas, num } \\
\text { possível retorno de configuração à } \\
\text { época do tombamento, em nada afeta } \\
\text { a estética. }\end{array}$ & $\begin{array}{l}\text { lluminação } \\
\text { pública, } \\
\text { mobiliário } \\
\text { urbano, } \\
\text { sinalização, e } \\
\text { elementos táteis } \\
\text { podem aumentar } \\
\text { a ocupação do } \\
\text { espaço de modo } \\
\text { mais } \\
\text { permanente e } \\
\text { diário, } \\
\text { aumentando o } \\
\text { uso do espaço } \\
\text { de forma } \\
\text { positiva. for }\end{array}$ & 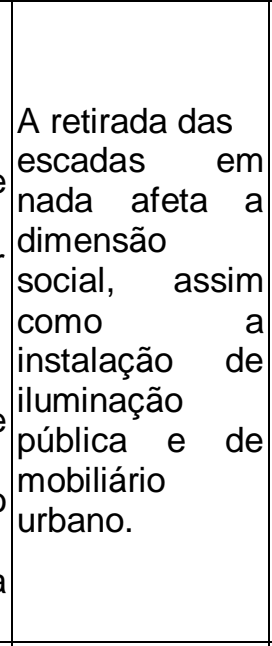 & $\begin{array}{l}\text { A realização } \\
\text { de estudos } \\
\text { sobre } \\
\text { autenticidade } \\
\text { e } \\
\text { acessibilidade, } \\
\text { podem evitar } \\
\text { adaptações } \\
\text { inadequadas. }\end{array}$ \\
\hline $\begin{array}{c}4 . \\
\text { Tradições e } \\
\text { Técnicas }\end{array}$ & $\begin{array}{l}\text { Novos elementos devem ser } \\
\text { marcados pelo contraste, mas não } \\
\text { devem destoar esteticamente dos } \\
\text { preexistentes, mas sim valorizá-los. }\end{array}$ & \begin{tabular}{|l} 
Técnicas \\
propostas \\
devem r estar \\
alinhadas com \\
as aplicadas \\
anteriormente. \\
\end{tabular} & $\begin{array}{l}\text { O espaço } \\
\text { requalificado } \\
\text { pode contribuir } \\
\text { para } \\
\text { preservação. }\end{array}$ & $X$ \\
\hline $\begin{array}{c}5 . \\
\text { Localização } \\
\text { e Espaço }\end{array}$ & $\begin{array}{l}\text { A inserção de novos elementos como } \\
\text { rampas e corrimãos não altera a } \\
\text { aparência da área externa e a } \\
\text { percepção do local. Sua instalação } \\
\text { deve ser estudada de modo a } \\
\text { respeitar materiais e desenho originais } \\
\text { e locais. A visibilidade do Convento, } \\
\text { proporcionada pelo Adro, pode ser } \\
\text { melhorada, contribuindo positivamente } \\
\text { com o fator estético na concepção do } \\
\text { conjunto. }\end{array}$ & $\begin{array}{|lr|}\text { As intervenções } \\
\text { podem r afetar } \\
\text { positivamente a } \\
\text { relação do } & \text { Adro } \\
\text { com } & \text { seu } \\
\text { entorno, r pois } \\
\text { podem rr r } \\
\text { requalificar } & \text { o } \\
\text { espaço } & \text { e } \\
\text { melhorar } & \text { a } \\
\text { fruição } & \text { do } \\
\text { mesmo r pela } \\
\text { comunidade. }\end{array}$ & $\begin{array}{l}\text { As intervenções } \\
\text { podem } \\
\text { contribuir para } \\
\text { uma maior } \\
\text { conscientização } \\
\text { da comunidade } \\
\text { quanto a a } \\
\text { preservação. }\end{array}$ & $\begin{array}{l}\text { As } \\
\text { intervenções } \\
\text { para } \\
\text { acessibilidade } \\
\text { não alteram } \\
\text { nem exigem } \\
\text { investigações } \\
\text { sobre } \\
\text { localização a } \\
\text { situação do } \\
\text { bem. }\end{array}$ \\
\hline $\begin{array}{l}\text { 6. Espírito e } \\
\text { Sentimento }\end{array}$ & $\begin{array}{l}\text { A melhoria urbanística geral que pode } \\
\text { ser conseguida com as intervenções } \\
\text { pode contribuir positivamente para } \\
\text { uma ressignificação do sentido de } \\
\text { posse do local. }\end{array}$ & $\begin{array}{l}\text { As intervenções } \\
\text { e a } \\
\text { requalificação } \\
\text { podem melhorar } \\
\text { a fruição do bem } \\
\text { pela comunidade } \\
\text { no uso religioso } \\
\text { e de } \\
\text { contemplação. }\end{array}$ & 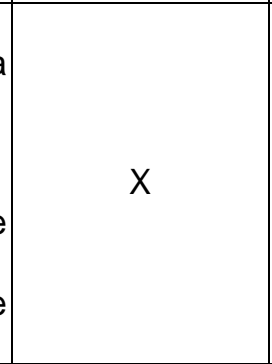 & $\begin{array}{l}\text { As } \\
\text { intervenções } \\
\text { não afetam as } \\
\text { dimensões } \\
\text { imateriais, tais } \\
\text { como espírito } \\
\text { e sentimento. }\end{array}$ \\
\hline
\end{tabular}

Fonte: Elaborada pelos autores. O "X" indica que o item não pode ser observado.

\section{CONCLUSÕES}

Apartir da coleta das informações obtidas para a elaboração das tabelas 1 e 2 e pela revisão dos conteúdos, em especial, da tabela 2, verifica-se a utilidade de ferramenta que é capaz de apresentar de maneira sucinta os valores patrimoniais, as necessidades e as restrições para as intervenções de adaptação para a acessibilidade e que, desta maneira, podem auxiliar aos 


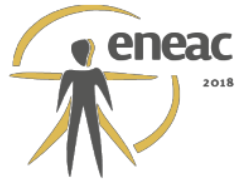

profissionais responsáveis pela intervenção a minimização de riscos de descaracterização. Identificou-se também, ao longo do estudo, que as intervenções necessárias de adaptação para acessibilidade não são de simples execução, especialmente as que afetam o aspecto Forma e Desenho, a menos que se admita a possibilidade de uma reconfiguração maior do Adro. Ao mesmo tempo, tal reconfiguração, embora represente também a necessidade maior de recursos financeiros para ser implementada, mostra-se adequada, pois além de se obter melhor acessibilidade obtém-se também o restauro do Adro à configuração espacial da época de seu tombamento, ou seja, final da década de 1930. A reconfiguração, no entanto, pode interferir em outros valores que se relacionam fortemente com a construção da identidade do lugar.

Entende-se que todas as intervenções devem considerar a possibilidade da manutenção e reutilização do máximo possível dos materiais originais, ou na impossibilidade, de materiais compatíveis com aqueles, em suas características físicas, químicas e mecânicas, tomando-se o devido cuidado para não falsificar ou gerar erros de interpretação. A escolha dos novos materiais deve levar em consideração a possibilidade de formação de pátina semelhante aos materiais originais. Deve-se priorizar também a utilização de materiais e elementos reversíveis, que possam ser substituídos, e mantidos e conservados, sem maiores danos ao bem, caso melhores opções surjam no futuro. Propostas de iluminação urbana, a instalação de mobiliário urbano e sinalização turística e tátil são ações de valorização que, no entanto, devem ser balizadas pelo bom senso e as especificidades inerentes aos centros históricos evitando-se assim a realização de um "estilo patrimônio", como apresentado por Leonardo Castriota (2009). A possível reconfiguração do Adro, à época do tombamento, favorecerá a reintegração e reabilitação do conjunto formado pelo largo do Cruzeiro, o Adro e o Convento, e as intervenções específicas do local devem estar alinhadas com o desenvolvimento de um plano de acessibilidade do sítio histórico da cidade deOlinda.

Para Sandra Ribeiro (2014), locais como o Adro do Convento franciscano, e outros pertencentes aos centros de cidades históricas, consagrados como patrimônio histórico e cultural, muitas vezes são palco de importantes manifestações culturais. A reabilitação e requalificação desses locais, incluindo as adaptações para acessibilidade, são possíveis e importantes para a história e cultura de um povo, com o reconhecimento de um objetivo social a ser alcançado. Este trabalho é apenas uma possibilidade de abordagem de um tema abrangente e, sobretudo urgente.

\section{REFERÊNCIAS BIBLIOGRÁFICAS}

ABNT. NBR 9050: Acessibilidade a edificações, mobiliário, espaços e equipamentos urbanos. Rio de Janeiro: ABNT, 2015. Disponível em: <http://www.pessoacomdeficiencia.gov.br/app/sites/default/files/arquivos/\%5Bfield_generico imagens-filefield-description\%5D_164.pdf>. Acesso em: 26 de abril de 2016>. Acesso: 6 jan. 2017.

BAZIN, G. A arquitetura religiosa barroca no Brasil, Volume II, Editora Record, Rio de Janeiro, Brasil, 1956.

BOTTALLO, M. PIFFER, M. POSER, P. Patrimônio da Humanidade no Brasil: suas riquezas culturais e naturais. UNESCO e Editora Brasileira de Arte e Cultura, Santos, Brasil, 2014.

BRASIL. Decreto Federal no 5.296/2004 (2004). Disponível em: <http://www.planalto.gov.br/ccivil_03/_ato2004-2006/2004/decreto/d5296.htm>. Acesso: 6 jan. 2017. 


\section{remen $^{\text {reme }}$}

Lei Federal no 13.146/2015 (2015). Disponível em: <http://www.planalto.gov.br/ccivil_03/_Ato2015-2018/2015/Lei/L13146.htm>. Acesso: 6 jan. 2017.

CARRAZZONI, M. L. Guia de bens tombados. Coordenação de Pesquisa de. Expressão e Cultura. Rio de Janeiro: Expressão e cultura, 1987.

CASTRIOTA, L. Patrimônio Cultural: Conceitos, políticas, instrumentos. São Paulo: Annablume, 2009.

FERREIRA, O. L. Patrimônio Cultural e Acessibilidade. As intervenções do Programa Monumenta, de 2000 a 2005 (Tese). Programa de Pesquisa e Pós-graduação da Faculdade de Arquitetura e Urbanismo PPG/FAU/UnB, Brasília, Brasil, 2011.

IPHAN. Instrução Normativa no 01, de 25 de novembro de 2003. Disponível em:

<http://portal.iphan.gov.br/uploads/legislacao/Instrucao_Normativa_n_1_de_25_de_novembr o_de_2003.pdf>. Acesso: 6 jan. 2017.

Instrução Normativa nํ 01, de 28 de fevereiro de 2014. Disponível em:

<http://pesquisa.in.gov.br/imprensa/jsp/visualiza/index.jsp?jornal=1\&pagina=5\&data=12/03/2 $014>$. Acesso: 6 jan. 2017.

MOREIRA, A. R. P. A Arqueologia Histórica na Cidade de Olinda. Olinda (PE): Centro de Estudos Avançados da Conservação Integrada - CECl, Brasil, 2007.

RIBEIRO, S. B. Mobilidade e Acessibilidade Urbana em Centros Históricos. Cadernos Técnicos

9, Iphan, 2014. Disponível em:

<http://portal.iphan.gov.br/uploads/ckfinder/arquivos/Caderno_mobildiade_acessibilidade_ur

bana.pdf>. Acesso: 6 jan. 2017.

ROWNEY, B. Charters and Ethics of Conservation: a cross-cultural perspective. (Thesis). School of Architecture, Landscape Architecture and Urban Design, Adelaide, Austrália, 2004. Disponível em:

<https://digital.library.adelaide.edu.au/dspace/handle/2440/37941>. Acesso: 6 jan. 2017.

UBIERNA, J. A. J. Accesibilidad Universal al Patrimonio Cultural. Fundamentos, criterios y pautas. Madrid: Real Patronato sobre Discapacidad, 2011. 